\title{
Discipline Disproportionality among Hispanic and American Indian Students: Expanding the Discourse in U.S. Research
}

\author{
Carolyn A. Brown ${ }^{1} \&$ Caterina Di Tillio ${ }^{1,2}$ \\ ${ }^{1}$ Graduate School of Education, Fordham University, New York, USA \\ ${ }^{2}$ New York City Department of Education, New York, USA \\ Correspondence: Carolyn Brown, Graduate School of Education, Fordham University, 113 W. $60^{\text {th }}$ Street, New \\ York, NY, USA. Tel: 1-212-787-1078. E-mail: cbrown39@fordham.edu
}

Received: May 25, 2013

doi:10.5539/jel.v2n4p47

\author{
Accepted: October 8, $2013 \quad$ Online Published: November 12, 2013 \\ URL: http://dx.doi.org/10.5539/jel.v2n4p47
}

\begin{abstract}
While disproportionality in discipline referrals and discipline action has been fairly well established among African American students in the United States, especially males in urban school districts, little research has looked at disproportionality among American Indian and Latino students. This paper uses a large dataset from the State of Arizona, with rich data on American Indian and Latino students, to explore if and how these students are being disproportionately referred for discipline and if and how these students are being punished more harshly for lesser violations than their peers. Results indicate that disproportionality in discipline referrals and in violation to action relationship for American Indians is on par with those of African Americans. Latino students were shown to be nearly proportional to their population.
\end{abstract}

Keywords: discipline referrals, American Indians, Latinos, discipline disproportionality

\section{Introduction}

School suspensions have nearly tripled since 1970 (Robers, Zhang, Truman, \& Snyder, 2012). Researchers have attributed this, in part, to the establishment of zero-tolerance policies instituted by states and school districts (Losen \& Skiba, 2010) in response to the Gun Free School Zones Act, requiring mandatory one year suspension for students found with weapons at school ("Gun Free School Zones Act", 1996). Suspensions and expulsions, referred to in this paper as removals, have increasingly become a standard punishment for offenses involving weapons, drugs, threats, bullying, harassment, property offenses and, in some cases, possession of items or substances that look like guns or drugs.

As removals have increased, research has consistently shown that suspensions have a negative effect on students' school success (Skiba \& Peterson, 2000). Suspensions fail to deter further discipline incidents and, in fact, contribute to dropping out (Wallace, Goodkind, Wallace, \& Bachman, 2008) and the likelihood of incarceration (Christle, Jolivett, \& Nelson, 2005). In addition, research has shown a disproportionality in the use of removal as punishment among African American students-particularly males and students with disabilities (Skiba, Michael, Nardo, \& Peterson, 2002; Townsend, 2000) - than White students. Disproportionality in removals among African American students has been attributed, in part, to these students being disproportionately referred for disciplinary action to the principal's office. In addition, African American students are more likely to receive removal as a consequence for low level discipline offenses such as "disruptive behavior" than their White peers (Skiba et al., 2002). While the "discipline gap" has been fairly well established between African American and White students, relatively little research has been conducted on disproportionality for Latino and American Indian students (Morrison \& D'Incau, 1997).

\section{Purpose}

The purpose of this study is to build on the current literature on disproportionality by examining office discipline referral (ODR) data and removal rates by racial group using data from the State of Arizona. Because Arizona uses a statewide system for collecting data on student violations and actions, the data offer nearly 300,000 records of ODR and action reports for the 2010-2011 school year. In addition, Arizona represents a particularly rich source of data on American Indian and Latino students because of the relatively high percentages of these students enrolled in public schools there. For this study, we conducted an initial analysis of ODR and removal 
rates by racial group, then we explored the relationship between the level of severity of the violation committed and level of disciplinary action, focusing on removals as they relate to race. The research questions that drove the analysis were:

- What are the ratios/proportions of ODR reporting and classroom removal by racial group and gender for the State of Arizona?

- Do different racial groups of students receive harsher discipline for similar misbehavior?

\section{Literature Review}

Research on disproportionality in ODR and removals has provided quantitative models for interpreting disproportionality in ODR and punishment for all races (Furlong, Morrison, Cornell, \& Skiba, 2004); even though, the vast majority of the studies have focused on African American students (Gregory, Skiba, \& Noguera, 2010; Skiba et al., 2002). Relatively little research has addressed disproportionality among Latino and American Indian students (Losen \& Gillespie, 2012; Wallace et al., 2008).

\subsection{Disproportionality and Discipline Referrals}

Studies have consistently demonstrated that African American children are referred for discipline more frequently and for less serious offenses, tend to be suspended for longer periods of time, and are more often subject to removal compared with their White peers (Losen \& Gillespie, 2012). (Fenning \& Rose, 2007; McFadden, Marsh, Price, \& Hwang, 1992).

Skiba, Peterson, and Williams (1997) found that most referrals for all students originate in the classroom with no "consistent relationship between seriousness of offense and severity of consequences" (p. 1). Researchers have found a pattern of disproportionality in the application of discipline based on race, gender, socio-economic status, and disability; however, regardless of whether poverty and other demographic factors are considered in the analysis, racial disproportionality in disciplinary practices has consistently been observed (Wallace et al., 2008).

Nelson, Gonzalez, Epstein and Brenner (2003) found that African American students were twice as likely as their White peers to receive a discipline referral. In addition, Skiba, Michael, Nardo and Peterson's (2002) review of racial and gender disparities in school punishments in an urban setting found that African American youth received disproportionately more referrals for subjective and nonviolent offenses, such as disrespect and excessive noise; whereas, White students were referred to the office more frequently for offenses that were easier to document objectively, such as smoking, vandalism, leaving without permission, and using profane language. Losen (2010) suggests that perhaps African American students may be involved in more subjective offenses or may be singled out.

\subsection{Disproportionality in Removal as Discipline}

Since the federal government began documenting school removals in 1970, disproportionate representation of racial minorities in school removal has been consistently documented and recent studies have confirmed the data (Gonzales \& Szecsy, 2004). Research has documented this pattern, particularly, for African Americans, as well as students with disabilities (Krezmien, Leone, \& Achilles, 2006; Perez, Skiba, \& Chung, 2008) and low-income students (Chen, 2008).

Skiba et al's (2002) comprehensive literature review on disproportionality found that the studies they reviewed met or exceeded the disproportionality criteria for African American students' school removal using either the baseline racial distribution or absolute proportion method. Review of the discipline disproportionality literature from the last five years continues to support the overrepresentation of African American youth in removal as a form of discipline. Studley (2002) examined discipline data from four of the six largest school districts in California for two years and found that African American students had the highest suspension rate of all racial groups.

Mendez and Knoff (2003) found similar results in their analysis of discipline data in the second largest school district in Florida. African American males were suspended at a rate higher than any other group at the elementary, middle, and high schools and at a much higher rate than their White peers. In middle schools, nearly half of African American males experienced suspension, compare to $25 \%$ of White students. For minor violations, African American males were suspended at a much higher rate than either White or Latino females at all school levels.

The overrepresentation of disciplinary exclusion of African American males begins at the elementary level and continues to high school. (Brooks, Schiraldi, \& Zeidenberg, 2000). In Phoenix, African American students were removed 22 times more than their White counterparts; in Austin and San Francisco the rate was nearly four times 
that of Whites (Losen \& Gillespie, 2012). A study conducted in Massachusetts found that although Latinos and Blacks comprised only $19.4 \%$ of the public school population, they represented $56.7 \%$ of school exclusions (Rabrenovic \& Levin, 2003).

Losen and Skiba (2010) looked at aggregated K-12 data from every state and found that $28.3 \%$ of African American males in middle schools were suspended, compared to only $10 \%$ of White students. The statistics aren't any better for females: $18 \%$ of African American females were suspended compared with only $3.9 \%$ of White females. When the researchers analyzed the data even further, they found that at least $30 \%$ of the African American males were suspended more than once. Some individual schools had extraordinarily high rates $-50 \%$ or higher for African American males. A number of studies have confirmed the disproportionality of the use of removal as discipline for African American students - especially males (Morrison, 1997; Townsend, 2000)

\subsection{Suspension and Disabilities}

In a four-year analysis, Zhang, Katsiyannis and Herbst (2004) found a relationship between race and disability and school suspension. For African American students at $25 \%$ of disabled students were suspended compared to $16 \%$ of non-disabled. The study found that numbers for American Indian students were not much better, with $11 \%$ of handicapped students suspended compared to $8 \%$ of students without disabilities. Losen and Gillespie (2012) also looked at states' rates for suspending students with disabilities and found that although the rates were highest for African American students, American Indians were suspended at much higher rates than their White counterparts. For example, in Illinois, $16.1 \%$ of American Indian students with disabilities were suspended compared to $7.8 \%$ of White students.

\subsection{Latino and American Indian Disproportionality}

Overall, few studies were found that included Latinos and even fewer that included American Indian students. Research on American Indian students is often limited because of the small number of American Indians included in most of the samples. However, research from American Indian scholars places great emphasis on alienation from school that results in low attendance as a major factor contributing to the failure of their students (Demmert \& Towner, 2003). Low attendance among American Indian students is well documented (Amiotte, 2008). Understanding how these students are treated in discipline and school removal is vital to increasing their sense of belonging in schools and ultimately their achievement.

A recent report from the Civil Rights Projects (Losen \& Gillespie, 2012) added important findings to this body of research by including Latino and American Indian students in an analysis of removal rates. The data from the Civil Rights Data Collection survey for 2009-2010 showed that in 2006, 15.9\% of American Indian males and $9.6 \%$ of females were suspended. These figures are higher when compared with White students' data (10\% for males and $4 \%$ for females) and particularly stark when considering that American Indian students comprise only $1.7 \%$ of the student population nationwide (U. S. Census Bureau, 2010). Nationally, American Indians were the next highest group after African Americans (17\% suspended), at $8 \%$ suspended. This is compared to $7 \%$ for Latinos, 5\% for Whites and 2\% for Asian Americans (Losen \& Gillespie, 2012). When considering individual state data, American Indians had the highest risk for suspension in eight states: North Carolina, Vermont, South Dakota, Utah, New Mexico, Montana and Idaho (Losen \& Gillespie, 2012). By disaggregating the data to the district level, the report illustrated wide variations in district policies toward suspension of racial groups. For example, districts were found to be suspending American Indians at rates ranging from $26.5 \%$ to $44.7 \%$.

Wallace et al. (2008) included findings on Latino and American Indian students in their study and found that these students, similar to African American students, were slightly more likely that White and Asian students to be referred to the office, but five times more likely to be removed. Losen and Skiba (2010) found that both Latino (16.3\% of boys, $8 \%$ for girls) and American Indian students $(15.9 \%$ for boys and $9.6 \%$ for girls) were suspended at a higher rate than White students (10\% for boys and $4 \%$ for girls), although at a lower rate than their African American peers (28.3\% for boys and $18 \%$ for girls).

Booker and Mitchell's (2011) study of placement in disciplinary alternative education settings and recidivism found that Latino students were 12 times more likely to be placed in a disciplinary alternative education setting than their White peers and 4.1 times more likely to return to the alternative setting within the same school year. This study (Booker \& Mitchell, 2011) did not include data on American Indian students. Booker and Mitchell (2011) concurred with studies indicating that White students were disciplined for more severe offenses, the findings were particularly remarkable in that Latino students were more likely than either White or African American students to be placed in alternative education programs for "administrator discretionary reasons" (p. 203). One study that relied on parent reports of removal found that the highest rates were for American Indian 
students (38\%) and African-American students (35\%), at an intermediate level for Latino students $(20 \%)$ and at the lowest level for White (15\%) and Asian American students (13\%) (Hoffman \& Llagas, 2003).

Our search for data on disproportionality in ODR turned up nothing on American Indian students. Skiba et al. (2011) included Latino students in their analysis of the relationships between ODR and punishments and found that Latino students, like African American student, were more likely to be more severely punished for lesser offenses.

\subsection{Outcomes for Excluded Students}

Removals are not effective in meeting the needs of any student (Skiba \& Peterson, 1999), and they often exacerbate the very problems they are attempting to reduce (Mayer, 1995). In recent years, qualitative research methods (e.g., narrative observations and open-ended interviews) have been used to examine the impact of school-wide discipline policies on students of color, primarily those with academic problems residing in high-poverty communities (Balfanz, Spirikakis, Neild, \& Legters, 2003). Collectively, the data resulting from this work support a link between the use of school-based removal discipline policies on students of color and their entry into the juvenile justice system (Fabelo, Thompson, \& Plotkin, 2011; Fenning \& Rose, 2007). This discipline gap produces negative outcomes such as dropout rates and low standardized test scores (Ekstrom, Goertz, Pollack, \& Rock, 1986; Gregory et al., 2010), which threaten the social development and futures of a large number of students.

Essentially, school-wide discipline data mirror juvenile justice and prison data in the overrepresentation of students of color (Wald \& Losen, 1996). Wallace et al. (2008) posit that the negative effects of removal are poor academic achievement, grade retention, delinquency, and substance abuse. Furthermore, suspension does not appear to work as a deterrent for future misbehavior (Mendez \& Knoff, 2003). Rather it has been found to be associated with additional suspensions and eventually expulsion or school drop-out (Losen \& Gillespie, 2012). Brooks, Schiraldi and Zeidenberg (2001) concur that repeated suspensions have been linked to a variety of negative outcomes, including academic failure, negative school attitudes, grade retention, and school drop-out.

\section{Methodology}

For our examination of disproportionality, we used simple ratio calculations for proportions and risk ratios to determine risk. To examine the relationships between severity of violation and severity of action, we arranged the violation and action data along a continuum and used logistic regression by racial group.

\subsection{Data Sources}

Data for this study were collected by the Arizona Department of Education from all school districts in the state for the 2010-2011 school year. The state-level database, AzSAFE, collected data for all reported student discipline incidents, the actions taken for each incident, and demographic and situational data for all individuals involved in every incident. The 2010-2011 data included data for all 589 districts in Arizona with a total of 285,329 reported incidents. Consistent coding of violations and actions is assured through a detailed set of definitions for all violations and actions, which were presented in a manual provided to all school personnel. In addition, school administrators were trained in the system. Each violation and action was coded at two or three levels, which allowed us to distribute the violations and actions over a continuum of severity in order to compare how disciplinary actions are meted out by violation according to student demographics.

For this particular study, Arizona provided a rich source of demographic data on American Indian and Latino students: American Indians, who comprise $1.7 \%$ of the U. S. populations (U. S. Census Bureau, 2010) constitute $5.4 \%$ of public school students in Arizona (National Center for Education Statistics, 2012), and similarly, 16.7\% of the U. S. population identifies as Latino (U. S. Census Bureau, 2010), but $41.4 \%$ of public school students in Arizona are identified as Latino (National Center for Education Statistics, 2012).

Our analysis for disproportionality used a selection of 116 districts with a total enrollment of 886,998 students. We included only districts that had 50 or more ODR in any one non-White racial category. This eliminated very small districts and districts with small non-White populations. Our analysis of severity of violation to severity of action included the full dataset for the state.

\subsection{Data Analysis}

To answer the first research question, our analysis for disproportionality used three ratio calculations for each of four categories: office discipline referral (ODR), in-school suspension (ISS), out-of school suspension (OSS), and expulsion (EXP). First, we calculated a composition index. We did this by calculating the percentage that 
each racial group comprised of the total number for each category to answer the question, for instance: Of the total number of referrals for the year, how many of them were American Indian students?

Total \# of ODR (ISS, OSS, Expulsion)/\# of referrals by (racial group) $=\%$ of referrals

Second, we examined how the total number of ODR, ISS, OSS, EXP in each racial group compared to the total enrollment for that racial group.

\section{Total \# (racial group)/\#(ODR, ISS, OSS, EXP) for (racial group)=\% of racial group for category}

Third, we used a relative risk ratio calculation for each category and for each racial group. A relative risk ratio compares the percentage of each racial group in each category (i.e., percent of Latinos given OSS) to the percentage of another racial group for the same category (i.e., percent of Whites given OSS). The resulting ratio identifies the relative risk that a Latino student will be given OSS compared to a White student. A relative risk ratio of 1.0 indicates proportionality (Perez et al., 2008).

To answer the second research question, the relationship between the severity of violation committed and the action taken by racial group, we used a logistic regression model to predict the relationship between violation and action. We took the additional step to analyze the data to limit the actions to how often ISS, OSS, and EXP were used and for which violations for each racial group.

\section{Theoretical Framework}

To adequately frame this study, we focused on theories that helped us understand power relationships among groups and within institutions, particularly as they relate to schools. First, although the AzSAFE system provides clear and specific categories for coding violations and actions, the decision to apply the actions to violations is fundamentally a human one. These decisions are based on individual attitudes and institutional norms that are deeply entrenched and often represent the needs and values of the historically dominant population. A critical theory lens that focuses on the power imbalance between the dominant group norms and marginalized populations (Morrow \& Torres, 1995; McLaren \& Giarelli, 1995) formed part of the theoretical framework for this study.

Our findings suggested that a second frame was needed to understand the social norms that favored punishment over positive interventions. Research in the field of psychology has shown that the exertion of power over students in the form of punitive action is rarely effective in preventing further negative behavior (Mayer, 1995); however, schools continue to use power structures in the form of punishment to "control" students. This issue of power overlaps the decision to impose punishment: first, there is the power of the school as an institution over the individual student, and second, there are the attitudes of the school authority as an individual to students as members of a marginalized population (Giroux, 1983). This complicated interplay of power between individuals and the school was used to frame our conclusions and our recommendations.

\section{Findings}

Overall, we found that for all four categories-ODR, ISS, OSS and EXP-American Indian students' rates of referral were similar to those for African Americans. Latino students were closer to proportionality that any other group, and White and Asian students had notably lower rates of ODR and removal.

\subsection{Disproportionality and Risk for ODR and Removals}

Focusing first on the range of students who were referred for discipline (ODR), we found that disproportionality was present, as expected, in gender ( $72 \%$ of referrals were males) and disability ( $18.2 \%$ referrals were students with disabilities who comprised only $11.7 \%$ of the populations) as well as race.

\subsection{Office Discipline Referrals}

For racial groups we found both over-referral and under-referral disproportionalities. While African American and American Indian students were notably over-referred, White and Asian students were notably under-referred. Only Latino students were found to be referred at rates proportional to the population (0.97). While African American's were $5.5 \%$ of the total population, they constituted $12.3 \%$ of ODRs for a composite ratio of 2.23; $70 \%$ of African Americans were referred for ODR. American Indians, who were $4.8 \%$ of the population, accounted for $10.2 \%$ of the referrals for a composite index of 2.12; $65 \%$ of American Indians were referred. For White's, the composite index was 0.67 and for Asians only 0.37. (See Table 1).

When the racial groups were compared to one another using the relative risk ratio, we found that African Americans and American Indians were at a higher risk of being referred for ODR than either their White or Latino peers. African Americans were 2.31 times more likely to be referred than Latinos and 3.18 times more 
likely to be referred than White students. American Indians were 2.17 more likely to be referred than Latinos and 2.98 more likely to be referred than Whites. When compared to one another, African Americans and American Indians were roughly at par for ODRs (0.94). When Latinos were compared to Whites, Latinos were found to be slightly (1.38 times) more likely to be referred (See Table 1).

\subsection{Removals}

For the entire state, there were 94,417 students referred for ISS, 85,659 students referred for OSS, and 403 student who were expelled. For ISS, we found that overall, the rates were similar for all racial groups, with American Indians students having the lowest rate composite index (.79). Whites were given ISS at a rate of 1.15, Asians at a rate of 1.10, Latinos at a rate of 1.07, and African Americans at a rate of 1.09. This contrasted sharply with the OSS rate for American Indians (See Table 1).

Table 1. Composite index for office discipline referrals, in-school suspension, out-of-school suspensions, and expulsions by racial group

\begin{tabular}{lllll}
\hline & Referrals & In-school suspensions & $\begin{array}{l}\text { Out-of-school } \\
\text { suspensions }\end{array}$ & Expulsions \\
\hline White & 0.67 & 1.05 & .97 & 1.06 \\
Asian & 0.37 & 1.10 & 1.1 & 1.0 \\
Latino & 0.97 & 1.07 & 1.1 & .90 \\
African American & 2.23 & 1.09 & 1.1 & 1.38 \\
American Indian & 2.12 & .79 & 1.19 & 1.20 \\
\hline
\end{tabular}

EXP was, overall, used relatively less often as an action than either ISS or OSS, which made the disproportionality more stark. American Indians were given OSS at a rate of 1.19 , which was only slightly higher than all other racial groups (Whites at .0.97; Asians, African Americans and Latinos at 1.1. However, African Americans and American Indians had higher composite indexes for EXP (1.38 and 1.20 respectively), while the other three groups lingered close to the 1.0 level (1.06 for Whites, 1.0 for Asians, and 0.90 for Latinos). Only students with disabilities were give EXP at a rate near that of the African Americans and American Indians (1.26). We were surprised that Whites and Asians, with a 0.37 and 0.67 rate of ODR (substantially below proportionality), were removed at roughly 1.0. These proportions became a bit more clear as we moved to our analysis of how violations are actioned.

\subsection{Risk Ratios}

Our findings for African American students were consistent with the literature. We compared African Americans for all four areas of ODR, ISS, OSS and EXP and found that the relative risk ratio for African American students was highest in all areas and in relation to all other racial groups. For ODR's African American students were 3.18 times more likely to be referred that Whites, 2.31 times more likely to be referred than Latinos, and 1.25 times more likely to be referred than American Indian students. African Americans were 1.31 more likely to be assigned to ISS or OSS, and 1.48 times more likely to receive EXP as Whites. They were 1.1 times more likely to be assigned to ISS, 1.2 times more likely to be given OSS and 1.6 times more likely to be EXP as Latinos; African Americans students were 1.7 times more likely to have ISS as American Indians, 1.4 times more likely to be given OSS and 1.6 times more likely to be EXP.

Because of the consistency of African American disproportionality in the literature and in our findings, we chose to calculate relative risk ratios for American Indian and Latino students against both White and African American students as a means of comparison.

While American Indians were nearly three times more likely to be referred for ODR (2.98) than their White peers, their ODR risk was roughly on par with African American students (.94). Compared with Whites, the risk of ISS and OSS were nearly the same (ISS=. 92, OSS=.92), but their risk of EXP was slightly higher at 1.14. Compared with African American students, American Indian students' risks of ODR and receiving OSS were nearly the same $(\mathrm{ODR}=.94$, OSS $=.92)$, but their risks of receiving ISS or being expelled were lower (ISS-.70, $\mathrm{EXP}=.77)$. 
Latino students were 1.38 times more likely to be referred for ODR. However, they were only slightly more at risk of receiving either ISS or OSS than their White peers $(\mathrm{ISS}=1.17, \mathrm{OSS}=1.17)$ and slightly less at risk for EXP $(\mathrm{EXP}=.92)$. Compared to the African American students, Latino students are less likely to be referred for ODR or removed $(\mathrm{ODR}=.43, \mathrm{ISS}=.89, \mathrm{OSS}=.89, \mathrm{EXP}=.86)$. When American Indians were compared to the Latino students for risk, we found that American Indian students are 2.17 more likely to be referred for ODR and 1.24 times more likely to be EXP. However, American Indians were less likely to receive ISS or OSS than Latinos $(\mathrm{ISS}=.79, \mathrm{OSS}=.79)$. (Note 1) $($ See Table 2$)$

Table 2. Relative risk ratios for American Indians and Latinos compared to African American and White students

\begin{tabular}{lllll}
\hline & Referrals & In-school Suspension & $\begin{array}{l}\text { Out-of-School } \\
\text { Suspension }\end{array}$ & Expulsion \\
\hline American Indians to White & 2.98 & .92 & .92 & 1.14 \\
$\begin{array}{l}\text { American Indian to } \\
\text { African Americans }\end{array}$ & .94 & .70 & .92 & .77 \\
Latino to White & 1.38 & 1.17 & 1.17 & .92 \\
Latino to African & .43 & .89 & .89 & .86 \\
American & & & .79 & 1.24 \\
American Indian to Latino & 2.17 & .79 & & \\
\hline
\end{tabular}

\subsection{Violations Severity, Removal, and Race}

For our exploration of the relationships between severity of violation and action, we conducted a logistic regression analysis. The AzSAFE dataset included 69 violation categories and 53 action categories, and the coding numbers for the violation and action categories were in no particular order. We reorganized each of the violations and actions into a progression of severity with the cooperation of the staff from the Arizona Department of Education who originally developed the AzSAFE program, and then we condensed the progression of violation categories into seven levels: $1=$ attendance violations (which were not addressed in this analysis, $2=$ minor offenses (such as disruptive behavior, disrespect, cheating, verbal provocation, and recklessness), $3=$ violations dealing with the possession and use of drugs and alcohol, $4=$ property damage (such as arson, burglary, vandalism, and theft, $5=$ harassment and threats (including bullying, sexual harassment, verbal and physical intimidation, $6=$ possession or use of dangerous items (weapons and items that could be used as weapons), and $7=$ violent crimes (such as assault, rape, endangerment, kidnapping, and homicide).

For actions, we condensed the actions into seven categories: $1=$ actions completed within one day (such as call to parents, demerit, apology), $2=$ actions completed in one day with legal involvement (local law enforcement contacted, drug test), $3=$ actions completed in one or more than one day (such as behavior contract, behavior intervention plan, threat assessment), $4=$ action completed in more than one day (detention, Saturday school, community service, restitution), 5=actions involving due process (disciplinary hearings, legal involvement), $6=$ suspension (with or without services), $7=$ expulsion (with or without services).

An initial correlation analysis found that for all racial groups, the most severe actions (most often ISS and OSS) were occurring at the low and mid level violations as well as the highest levels of violations. That is, violations such as "disruptive behavior" and "disrespect" were being actioned with ISS and OSS as were level six and seven violations that required legal action. The overall removal rates were highest for levels three and seven violations, but no differences were seen by racial group. For level three violations, between $25.3 \%$ and $31.6 \%$ of students were removed. At level seven, removal rates ranges from $46.7 \%$ to $52.6 \%$. All other violations levels showed removal rates under $10 \%$.

To consider only ISS, OSS, and EXP between the six violation categories and the three removal categories we used logistic regression and measured significance with the Wald statistic, we did find differences between racial groups - particularly among American Indians and Asian students. No significance was found for a relationship between any of the violation categories and EXP. For all racial groups, the EXP rate was low (less than 10\%). However, for ISS and OSS some differences were apparent. While the relationship between violation level and ISS was significant for all six violation categories for White students, significance between violation level and 
OSS was found for level three, five, and six only. This is consistent with the most severe actions occurring at violation level three.

For African American students, the relationship between violation and ISS showed no significance at all; however, only the relationship between level three violations and OSS was significant. For Latino students the relationship between violation category and ISS took an unexpected turn and was significant in all but the level three violation. For OSS, the relationship with violation was significant at all levels except level four.

We found few significant relationships between violation levels and ISS and OSS for American Indian students. For ISS, violation level was significant only at levels two and four, and for OSS only at level three and five for American Indian students. Asian students showed a significant relationship between ISS and level two, four and five and for OSS at level two, three and five. Table 3 illustrates these data with names for the violation levels. Significance is indicated by bold type.

Table 3. Logistic regression significance between violation level and ISS and OSS by racial group

\begin{tabular}{llllllllllll}
\hline Violation & \multicolumn{2}{c}{ White } & \multicolumn{2}{c}{ Afri-Amer } & \multicolumn{2}{c}{ Latino } & \multicolumn{2}{c}{ Amer Ind } & \multicolumn{2}{c}{ Asian } \\
& ISS & OSS & ISS & OSS & ISS & OSS & ISS & OSS & ISS & OSS \\
\hline Level 2-Minor Offenses & $\mathbf{0 . 0 0}$ & 0.12 & 0.56 & 0.51 & $\mathbf{0 . 0 0}$ & $\mathbf{0 . 0 5}$ & $\mathbf{0 . 0 0}$ & 0.52 & $\mathbf{0 . 0 0}$ & $\mathbf{0 . 0 0}$ \\
Level 3-Substance & $\mathbf{0 . 0 0}$ & $\mathbf{0 . 0 0}$ & 0.70 & $\mathbf{0 . 0 0}$ & 0.07 & $\mathbf{0 . 0 0}$ & 0.06 & $\mathbf{0 . 0 0}$ & 0.59 & $\mathbf{0 . 0 0}$ \\
Level 4-Property Offenses & $\mathbf{0 . 0 0}$ & 0.53 & 0.70 & 0.70 & $\mathbf{0 . 0 0}$ & 0.96 & $\mathbf{0 . 0 0}$ & 0.58 & $\mathbf{0 . 0 0}$ & 0.37 \\
Level 5-Harrassment/Threat & $\mathbf{0 . 0 0}$ & $\mathbf{0 . 0 0}$ & 0.40 & 0.32 & $\mathbf{0 . 0 0}$ & $\mathbf{0 . 0 0}$ & 0.07 & $\mathbf{0 . 0 0}$ & $\mathbf{0 . 0 0}$ & $\mathbf{0 . 0 0}$ \\
Level 6-Dangerous Items & $\mathbf{0 . 0 0}$ & $\mathbf{0 . 0 1}$ & 0.83 & 0.77 & $\mathbf{0 . 0 0}$ & $\mathbf{0 . 0 2}$ & 0.30 & 0.21 & 0.26 & 0.04 \\
Level 7-Violent Offenses & -- & -- & -- & -- & -- & -- & -- & -- & -- & -- \\
\hline $\mathrm{p}=.05$ & & & & & & & & & & &
\end{tabular}

\section{Conclusion and Discussion}

Our research concurred with previous literature on disproportionality among African American students for office discipline referrals and removals when compared to their White peers. We found that both American Indian and Latino student were at greater risk of receiving an office discipline referral and assigned in-school or out-of-school suspension than their White peers. American Indians, particular, were disproportionately at risk of being receiving an office discipline referral than their White and Latino peers and nearly at par with African American students. Even more troubling is that American Indian students were at greater risk of being expelled from school than White and Latino students and only slighter at lesser risk than African American students. This was particularly significant for violations involving substance use and harassment or threat. Overall, Latino students were found to be mostly at par in proportionality for office discipline referrals and all forms of removal. They were only slightly more likely than their White peers to received an office discipline referral and assigned in-school or out-of-school suspension, while slightly less likely at risk for expulsion.

The logistic regression results were somewhat more puzzling. Overall, we found significant relationship between low level offense (minor offenses or substance related offenses) and out-of-school suspension for all racial groups. Only Latino and Asian-American students showed significant relationships between low level offenses and out-of school suspension, while only White and American Indian student's showed significant rates of in-school suspension for low level offense (which would be expected). However, at the highest level of violations (dangerous items or violent offense), only White and Latino student had significant rates of out-of-school suspension. We interpret these findings tentatively, as the categorization of the violations may not have adequately reflected the severity of the violation and we were not able to track student recidivism over the year for the data (and were working with only one year of data). It is possible that students were suspended for low level violations after multiple offenses that we did not track.

\subsection{American Indian Students}

Expulsion is a troubling finding for American Indian students because, as noted in the literature, absenteeism and alienation from school are major factors in the failure of American Indian students to succeed in school (Demmert \& Towner, 2003). Absenteeism is the single largest issue impeding American Indian student's school success (Ruberg, 2008) and contributing to the high drop out rate among these students (Hilfiker, 2009). As we 
have shown from the literature, classroom and school removal do not act to reduce further violations, but in fact, increase the potential for further violations (Iselin, 2010; Losen \& Gillespie, 2012; Mendez, 2003). School removal and particularly the permanence of expulsion have been shown to be counter-productive in keeping students in school and, in fact, contribute to dropping out and involvement with the juvenile justice system that frequently interrupts a student's education (Mendez, 2003).

While the AzSAFE system does include a violation category for absenteeism, we found few entries in that category. Most schools record absenteeism in a separate database in order to meet mandatory state requirements for average daily attendance, the requirement for which precedes the AzSAFE and is well institutionalized. This separation of record keeping is a vital issue in understanding our findings because, while recording daily attendance is mandated by the Arizona Department of Education, the use of AzSAFE is not. Our data shows that substance use and harassments and threats are the only two violation categories that were significant with out-of-school suspension for American Indians. While the AzSAFE system records these violations, the more persistent and troubling issue of absenteeism omitted from school administrators' analysis of discipline data from the AzSAFE system.

\subsection{Institutional and School Decisions}

The data from Arizona do not indicate that schools were over using expulsion as a punishment, with fewer than 700 expulsions recorded in the AzSAFE database for the 2010-2011 year, and yet, American Indians and African Americans were consistently at greater risk of being expelled. While in-school and out-of-school suspension assignments can be made by school principals, expulsions often require some kind of meeting with the school district superintendent or hearing with district personnel and law enforcement. The disproportionality between these two groups asks us to consider how the school institutions, both school and district level, view these populations. Our understanding of the American Indian cultures, their alienation from school, and public school's historical reluctance to accommodate the cultural and individual needs of these students (Pewewardy \& Cahape, 2003; Ruberg, 2008; Swisher \& Hoisch, 1992) leads us to question if a power imbalance between school and district personnel (or the institutional values of the schools) and the American Indian communities may contribute to the disproportionality in removals.

\subsection{Entry and Use of Data}

Another factor that needs to be considered in interpreting our findings is the fidelity with which school administrators enter and use the data in the AzSAFE system. The value of state level office discipline referral systems are mitigated by two factors: how consistently and how accurately school administrators enter daily violation and action data and if and how they choose to analyze and use these data to implement programs for improving school climate and safety. How consistently data is entered into the system is influenced by a number of elements: first, federal regulations, which were tied to No Child Left Behind (NCLB) in 2002, require that states report data about youth drug use and school violence at the state and local levels. "States must provide information on a school-by-school basis on: truancy rates; the frequency, seriousness, and incidence of violence and drug-related offenses resulting in suspensions and expulsions in elementary schools and secondary schools entities" ("Safe and Drug Free Schools Act," 2001). In addition, the Gun Free School Zones Act, also tied to NCLB requires states to report, annually, on school districts' implementation of a policy requiring referral to the criminal justice system of any student who brings a firearm to school. These reports must include information on the student's expulsion. ("Gun Free School Zones Act," 1996). These two regulations may account for the common significance of substance abuse (violation level three) and out-of-school suspension across all racial groups and the increase in significance for out-of-school suspension and level six (dangerous items) for White and Latino students. Surprisingly, significance in this later relationship between dangerous items and out-of-school suspension was not seen for African American or American Indian students; however, when we consider the in-school and out-of-school suspension for these two groups for lower level violation, we are left with a number of questions about how African American and American Indian students are disciplined. How many are removed for low level violation and subsequently drop out of school or become involved in the juvenile justice system?

Another important element in the collection and recording of data is related to the legal structure of state departments of education and local school districts in the West and the South. In many Western and Southern states, departments of education can develop systems such as AzSAFE, but they cannot mandate that districts use them. In Arizona, for instance, districts use a variety of student management software systems (SMS), which collect office discipline referral and violation and action data at various levels of detail. Even though the Arizona State Department of Education has put substantial resources into working with the companies that produce these 
proprietary SMS systems, full alignment with the AzSAFE system has not been achieved. So, district and school administrators in Arizona can choose to use AzSAFE or they can use the SMS system that they currently have. Technical support staff at the state department of education, then, translate the proprietary SMS data to the AZSafe system with various levels of accuracy. (Note 2)

The final element in the collection and entering of data has to do with the commitment of the school administrators to tracking and using the data. In states like Arizona where the collection can not be mandated, which students office discipline referral and records of violations and action end up the data base may be related to a number of factors: Administrator time, commitment to tracking actual data as opposed to being comfortable with their perceptions of which students are violators, and training on and comfort with the system. Over $91 \%$ of violations were committed by students who had committed more than one violation in the 2010-2011 school year in every racial category except African American where only $86 \%$ of the student were repeat offenders. This would indicate that single incident violators may be less likely to be entered into the system. How does an administrator's or teacher's perception of a student and his or her potential for committing a second violation influence their decision to process an office discipline referral or enter it into the system or their decision to use a harsher punishment?

Exploring how the data are used to implement programs that improve school climate was beyond the scope of this study, but in our work with disproportionality we have considered that a relationship may exist between a school administrator's willingness to take the time to collect the data and his or her intention to implement school climate improvement. While some districts and schools have a commitment to a positive school climate, we question how many are more motivated to understand how violations are being actioned and who is involved as opposed to those where administrators are comfortable with their "knowledge" of their students. Are teachers and administrators satisfied with their perceptions of student behavior or are they open to data that may indicate discrepancies in their perceptions? Good data on school discipline can challenge the common perceptions of teachers and administrators of who the "bad" students are and unsettle the power balance in a school-administrators and teachers in charge, and certain races lack of participation in the school power structure. The use of data for tracking student achievement, which has been implemented in states and districts across the country since the passage of NCLB, has focused the conversation about where resources need to be spent to improve student achievement. School climate has been shown, albeit tentatively, to have an impact on school quality and student achievement (Brookover \& Lezotte, 1979; Chen, 2007). Data on student behavior and how school personnel are treating it are an important next step in school improvement.

\section{Further Research}

Suggestions for further research are endless. We are particularly interested in how office discipline referral and violation and action data are being used in districts that are collecting the data with fidelity and if they are using the data to implement programs or simply collecting it to meet requirements. Research on intervention programs for student offenders as well as research on school climate is plentiful; however, research that focuses specifically on meeting the social emotional needs of students of color is scant, particularly for American Indian students. Research on American Indian students, in particular, has focused on how the perceptions of teachers and administrators affect students' attitudes toward school and their social and emotional sense of safety and belonging that is vital to their participation in formal schooling (Pavel, 1999; Pewewardy \& Cahape, 2003).

Research has consistently indicated that safe and orderly climates are a significant factor in high quality schools (Leithwood \& Riehl, 2003). While the "achievement gap" between racial groups continues to dominate the discussion of student success and quality schools, a commitment to using data to understand and develop intervention to create safe and orderly schools remains on the margins of the discourse. The "discipline gap" has only begun to enter the discussion. Both research and legislation action is required. AzSAFE provided a giant step toward collecting data at the state level. With only four other states using statewide data systems, much remains to be done

\section{References}

Amiotte, S. (2008). Bureau of Indian Education and tribal school leaders' perceptions of school-level factors leading to academic achievemenet for Native American students. (doctoral dissertation), University of South Dakota, Vermillion, SD. (AAT 3333965)

Balfanz, R. K., Spirikakis, K., Neild, R. C., \& Legters, N. (2003). High poverty secondary schools and the juvenile justice system: How neither helps the other and how that could change. San Francisco: Jossey-Bass. 
Booker, K., \& Mitchell, A. (2011). Patterns in recidivism and discretionary placement in disciplinary alternative education: The impact of gender, ethnicity, age, and special education status. Education and Treatment of Children, 34(2), 193-208.

Brookover, W. B., \& Lezotte, L. W. (1979). Changes in school characteristics coincident with changes in student achievement (Occasional Paper No 17). East Lansing: Michigan State University: East Lansing Institute for Research in Teaching.

Brooks, K., Schiraldi, V., \& Zeidenberg, J. (2001). School house hype: Two years later. Washington, DC: Justice Policy Institute, Childrens Law Center.

Brooks, K., Schiraldi, V., \& Zeidenberg, J. (2001). School house hype: Two years later. San Francisco: Justice Policy Institute.

Chen, G. (2007). School disorder and student achievement: A study of New York City elementary schools. Journal of School Violence, 6(1), 27-43. http://dx.doi.org/10.1300/J202v06n01_03

Chen, G. (2008). Communities, students, schools, and school crime: A confirmatory study of crime in U.S. high schools. Urban Education, 43(3), 301-318. http://dx.doi.org/10.1177/0042085907311791

Christle, C. A., Jolivett, K., \& Nelson, C. M. (2005). Breaking the school to prison pipeline: Identifying school risk and protective factors for youth deliquency. Exceptionality, 13(2), 69-88. http://dx.doi.org/10.1207/s15327035ex1302_2

Demmert, W. G., \& Towner, J. C. (2003). A review of the research literature on the influences of culturally based education on the academic performance of Native American students. Portland, OR: Northwest Regional Education Laboratory, U.S. Department of Education.

Ekstrom, R. B., Goertz, M. E., Pollack, J. M., \& Rock, D. A. (1986). Who drops out of high school and why? Findings from a national study. Teachers College Record, 87(2), 357-373.

Fabelo, T., Thompson, M. D., \& Plotkin, M. (2011). Breaking school rules: A statewide study of how school discipline relates to students' success and juvenile justice involvement. New York: Justice Center: The Council of State Governments and Public Policy Research Institute.

Fenning, P., \& Rose, J. (2007). Overrepresentation of African American students in exclusionary discipline: The role of school policy. Urban Education, 42(6), 536-559. http://dx.doi.org/10.1177/0042085907305039

Furlong, M. J., Morrison, G. M., Cornell, D. G., \& Skiba, R. J. (2004). Methodological and measurement issues in school violence research: Moing beyond the social problem era. Journal of School Violence, 3(2), 5-12. http://dx.doi.org/10.1300/J202v03n02_02

Giroux, Henry A. (1983). Theories of reproduction and resistance in the new sociology of education: A critical analysis. Harvard Educational Review, 53(3), 257-293.

Gonzales, J. M., \& Szecsy, E. M. (2004). The condition of minority access and participation in Arizona. Tempe, AZ: University of Arizona.

Gregory, A., Skiba, R. J., \& Noguera, P. A. (2010). The achievement gap and the discipline gap: Two sides of the same coin? Educational Researcher, 39(1), 59-68. http://dx.doi.org/10.3102/0013189X09357621

Hilfiker, M. (2009). Dropout prevention focus on American Indian youth. Denver, CO: North Central Comprehensive Center, U.S Department of Education.

Hoffman, K., \& Llagas, C. (2003). Status and trend in the education of Blacks (NCES 2003-034). Washington, DC: U. S. Department of Education, National Center for Education Statistics.

Iselin, A. M. (2010). Research on school suspension. Paper presented at the North Carolina Family Impact Seminar: School Suspension: Research and Policy Options, North Carolina General Assembly.

Krezmien, M. P., Leone, P. E., \& Achilles, G. M. (2006). Suspension, race and disability: Analysis of statewide practices and reporting. Journal of Emotional and Behavioral Disorders, 14(4), 217-226. http://dx.doi.org/10.1177/10634266060140040501

Leithwood, K. A., \& Riehl, C. (2003). What we know about successful school leadership: A report by Division A of AERA. Washington, DC: National College for School Leadership, .

Losen, D. J., \& Gillespie, J. (2012). Opportunities suspended: The disparate impact of disciplinary exclusion from school. Los Angeles: The Center for Civil Rights Remedies, The Civil Rights Projects, UCLA. 
Losen, D. J., \& Skiba, R. J. (2010). Suspended education: Urban middle schools in crisis. Retrieved from http://www.splcenter.org

Mayer, G. R. (1995). Preventing antisocial behavior in the schools. Journal of Applied Behavior Analysis, 28, 467-478. http://dx.doi.org/10.1901/jaba.1995.28-467

McFadden, A. C., Marsh, G. E., Price, B. J., \& Hwang, Y. (1992). A study of race and gender bias in the punishment of handicapped school children. Urban Review, 24, 239-251. http://dx.doi.org/10.1007/BF01108358

McLaren, P. L., \& Giarelli, J. A. (1995). Critical theory and educational research. Albany: State University of New York Press.

Mendez, L. M. (2003). Predictors of suspension and negative school outcomes: A longitudinal investigation. New Directions for Youth Development, 99, 17-33. http://dx.doi.org/10.1002/yd.52

Mendez, L. M., \& Knoff, H. M. (2003b). Who gets suspended from school and why? A demographic analysis of schools and disciplinary infraction in large school districts. Education and Treatment of Children, 26(1).

Morrison, G. M. (1997). The web of zero-tolerance: Characteristics of students who are recommended for expulsion from school. Education and Treatment of Children, 20(3), 316.

Morrison, G. M., \& D'Incau, B. (1997). The web of zero tolerance: Characteristics of students who are recommended for expulsion from school. Education and Treatment of Children, 20, 316-335.

Morrow, R. A., \& Torres, C. A. (1995). Social theory and education. Albany: State University of New York Press.

National Center for Education Statistics. (2012). Digest of education statistics. Retrieved August 8, 2012, from http://nces.ed.gov/programs/digest/d03/tables/dt147.asp

Nelson, J. R., Gonzales, J. E., Epstein, M. H., \& Benner, G. J. (2003). Administrative discipline contacts: A review of the literature. Behavioral Disorders, 23(4), 249-281.

Pavel, D. M. (1999). Schools, principals, and teachers serving American Indian and Alaska Native students. ERIC Digest. Retrieved from http://www.ericdigsts.org/1999.html

Perez, B., Skiba, R. J., \& Chung, C. G. (2008). Latino students and disproportionality in special education Education Policy Brief. Bloomington, IN: Center for Evaluation and Education Policy, Indiana University.

Pewewardy, C.-H., \& Cahape, P. (2003). Culturally responsive teaching for American Indian students. ERIC Digest. Retrieved from http://www.ericdigests.org/2005-1/teaching.htm

Rabrenovic, G., \& Levin, J. (2003). The quality of post exclusion assignments: Racial and ethnic differences in post-exclusion assignments for students in Massachusetts. Paper presented at the School to Prison Pipeline Conference, Harvard University, Cambridge, MA.

Robers, S., Zhang, J., Truman, J., \& Snyder, T. D. (2012). Indicators of school crime and safety: 2011. Washington, DC: Institute of Education Science and Bureau of Justice Statistics, US Department of Education and U.S. Department of Justice.

Ruberg, R. S. (2008). In or out? Predictors of educational attainment in American Indian youth (doctoral dissertation). Tulane University School of Science and Engineering, New Orleans, LA. (AAT 3321032)

Skiba, R. J., Horner, R. H., Chung, C.-G., Rauch, M. K., May, S. L., \& Tobin, T. J. (2011). Race is not neutral: A national investigation of African American and Latino disproportionality in school discipline. School Psychology Review, 40(1), 85-107.

Skiba, R. J., Michael, R. S., Nardo, A. C., \& Peterson, R. L. (2002). The color of discipline: Sources of racial and gender disproportionality in school punishment. The Urban Review, 34(4), 317-342. http://dx.doi.org/10.1023/A:1021320817372

Skiba, R. J., \& Peterson, R. L. (1999). The dark side of zero tolerance: Can school punishment lead to safer schools? Phi Delta Kappan, 80, 381-382.

Skiba, R. J., \& Peterson, R. L. (2000). School discipline at a crossroads: From zero tolerance to early response. Exceptional Children, 66(2), 335-346.

Skiba, R. J., Peterson, R. L., \& Williams, T. (1997). Office referrals and suspension: Disciplinary intervention in middle schools. Education and Treatment of Children, 20, 1-21. 
Studley, S. R. (2002). The impact of zero tolerance school discipine policies on school crime rates: How suspensions and expulsions affect African American and special education students. Dissertation Abstracts International, 63(4).

Swisher, K., \& Hoisch, M. (1992). Dropping out among American Indians and Alaska Natives: A review of studies. Journal of American Indian Education, 31(2), 3-23.

Townsend, B. L. (2000). The disproportionate discipline of African American learners: Reducing school suspensions and expulsions. Exceptional Children, 66(3), 381-391.

U. S. Census Bureau. (2010). United States Census. Washington, DC. Retrieved from http://www.census.gov

Wald, J., \& Losen, D. J. (1996). Integrated approaches to preventing anti-social behavior patterns among school aged children and youth. Journal of Emotional and Behavioral Disorders, 4(4), 194-210. http://dx.doi.org/10.1177/106342669600400401

Wallace, J. M., Goodkind, S., Wallace, C., \& Bachman, J. G. (2008). Racial, ethnic and gender differences in school discipline among U.S. high school students: 1991-2005. The Negro Educational Review, 59(1-2), $47-62$.

Zhang, J., Katsyannis, A., \& Herbst, M. (2004). Disciplinary exclusion in special education: A four-year analysis. Journal of Behavioral Disorders, 29(4), 337-347.

\section{Notes}

Note 1 . This analysis found, in addition, that although Asians were .57 less likely to be referred than their White peers, they were 1.2 times as likely to be assigned to ISS or OSS and 1.3 times as likely to be EXP.

Note 2. Kentucky, West Virginia, and Pennsylvania all have statewide ODR/Violation and Action systems that compare with Arizona's in detail and comprehensiveness. Kentucky and West Virginia's systems are able to be mandated by state legislation.

\section{Copyrights}

Copyright for this article is retained by the author(s), with first publication rights granted to the journal.

This is an open-access article distributed under the terms and conditions of the Creative Commons Attribution license (http://creativecommons.org/licenses/by/3.0/). 